\title{
Material Studies of Historic Inks: Transition from Carbon to Iron-Gall Inks
}

\author{
Ira Rabin
}

\begin{abstract}
This chapter offers observations and considerations concerning black writing inks encountered in writing supports transmitting documentary and literary texts of the late Antiquity and early Middle Ages. It discusses different types of inks, the methods of their detection and their use in different times and geographical areas.
\end{abstract}

\section{Keywords}

writing inks - ink fingerprint - material analysis

The transition period from carbon ink, commonly associated with Antiquity, to iron-gall ink, extremely popular in the medieval Middle East and Europe, provides the focus for our investigative work. Our studies combine a search of extant written records with an experimental determination of the ink composition in selected, preferably dated and localized manuscripts. ${ }^{1}$ Though

1 Claudia Colini, From Recipes to Material Analysis: the Arabic Tradition of Black Inks and Paper Coatings (9th to 2oth century), (PhD Diss., Hamburg University, 2018); Zina Cohen, Composition Analysis of Writing Materials in Geniza Fragments, (PhD Diss., BAM, EPHE and Hamburg University, 2020); Tea Ghigo, Systematic Scientific Approach to the Study of Inks from Coptic Manuscripts, (PhD Diss., BAM, Sapienza Rome and Hamburg University, 2020). Much of the research presented here is carried out in the context of the SF B $95^{\circ}$ 'Manuskriptkulturen in Asien, Afrika und Europa,' funded by the German Research Foundation (Deutsche Forschungsgemeinschaft, DFG) and within the scope of the Centre for the Study of Manuscript Cultures (CSMC). I would like to acknowledge the help of the personnel of the museums, archives and libraries who grant access to manuscripts and support this work. My thanks go to Oliver Hahn, the head of the BAM 4.5 division, for his contribution and other department members at the BAM and CSMC who participate in this research: Olivier Bonnerot, Sebastian Bosch, Zina Cohen, Claudia Colini, Ines Feldmann, Tea Ghigo and Ivan Shevchuk. My special thanks go to my husband, Marcello Binetti, for fruitful discussions and proof-reading of the manuscript. 
ink studies have become increasingly popular in the last five to ten years, no large-scale research in this field has yet been conducted and, therefore, a general picture cannot be drawn at this stage.

To outline the inks of the transition period, we begin with the definitions of known inks, their properties and the techniques that are used to identify and study them.

One of the oldest writing and drawing pigments is produced by mixing soot or charcoal with a binder dissolved in a water soluble medium. Thus, along with soot, binders such as gum arabic (ancient Egypt) or animal glue (China) form the main components of soot inks. These inks were usually stored as dry cakes. To produce a writing liquid, they were mixed with water directly before an inscription was planned. Carbon inks form a suspension and, therefore, do not penetrate a substrate (papyrus, parchment or sized paper), but are well localized on the surface. Traditionally, one identified carbon inks using infrared photography, since their deep black colour does not change under infrared light. In recent decades, Raman spectroscopy has become more popular in the identification of carbon inks and it was hoped that this method would distinguish between charcoal and soot as precursors for the ink. Unfortunately, this is not yet the case. Similarly, the claim that Raman spectroscopy can be used as a non-invasive dating tool remains unsubstantiated. ${ }^{2}$ There is a number of extant recipes, ranging from the late Antiquity ${ }^{3}$ to the Middle Ages. ${ }^{4}$ Carbon inks containing a considerable amount of copper were detected on a small number of the Dead Sea Scrolls. ${ }^{5}$ Recently, carbon inks containing significant

2 Sarah Goler, James T. Yardley, Angela Cacciola, Alexis Hagadorn, David Ratzan, Roger Bagnall, "Characterizing the Age of Ancient Egyptian Manuscripts though Micro-Raman Spectroscopy," Journal of Raman Spectroscopy, 2016, 47:1185-93.

3 Dioscorides, De materia medica. Codex Neapolitanus, Napoli, Biblioteca nazionale, Ms. Ex. Vindob. Gr. 1, kommentiert von Carlo Bertelli, Salvatore Lilla, Guglielmo Cavallo, 2 vols, Rom: Salerno Editrice / Graz: Akademische Druck- und Verlagsanstalt, 1988/1992; Pliny, The Natural History: in 10 volumes, vol. 9: Books XXXIII-XXXv, ed. and transl. by Harris Rackham, Cambridge, MA: Harvard University Press 1995 (The Loeb Classical Library 394; reprint).

4 Armin Schopen, Tinten und Tuschen des arabisch-islamischen Mittelalters, (Göttingen: Vandenhoeck \& Ruprecht, 2014).

5 Yoram Nir-El, and Magen Broshi, "The Black Ink of the Qumran Scrolls," Dead Sea Discoveries, 1996, 3:158-167. 
quantities of lead $(\mathrm{Pb})$ were identified on a Herculaneum papyrus. ${ }^{6}$ Given that, in both cases, carbon constitutes the colorant of the inks we consider these varieties to belong typologically to the class of carbon inks.

\section{$2 \quad$ Plant Inks}

Plant or tannin inks are solutions of tannins extracted from various plants and are brown in colour. Plant inks are absorbed by the substrate; the degree of absorption largely depends on the nature of that substrate. They have a characteristic homogeneity and show no crystallization. They gradually fade under light of a growing wavelength and become transparent under light of ca. $75^{\circ} \mathrm{nm}$. They are best identified by their physical and optical properties. The most well-known plant ink, at least for the Western Middle Ages, is the thorn or Theophilus' ink, ${ }^{7}$ the elaborate recipe for which is recorded in Theophilus' 12 th century work De diversis artibus. ${ }^{8}$ Another recipe is offered by Martianus Capella in his encyclopedic work. Unfortunately, no systematic study of the historical use of these inks has been compiled: their use has been only occasionally reported in different scriptoria. Inks of brown-reddish colour in Near East manuscripts have also been identified as pure vegetable extracts. ${ }^{9}$

\section{3}

\section{Iron-Gall Inks}

Iron-gall inks dominated the black to brown palette of writing materials in the manuscripts ranging from the Middle Ages to the 19th century. They are produced by the reaction between iron(II) and gallic acid, which results, initially, in a colourless, soluble complex that forms black, water-insoluble pigment upon oxidation. In addition, a great variety of medieval to modern recipes name various water-soluble binders and solvents such as water, wine or vinegar that

6 Emmanuel Brun, Marine Cotte, Jonathan Wright, Marie Ruat, Pieter Tack, Laszlo Vincze, Claudio Ferrero, Daniel Delattre, Vito Mocella, "Revealing Metallic Ink in Herculaneum papyri," 2016, Proceedings of the National Academy of Sciences of the United States of America. 113, 201519958. <https://doi.org/10.1073/pnas.1519958113> (last accessed 13th March 2019).

7 Monique Zerdoun Bat-Yehouda, Les encres noires au Moyen Âge: jusqu'à 1600 (Paris: CNRs, 1983), pp. 156-165 offers a detailed discussion of this ink, which could be a plant ink or an imperfect iron-gall ink if one translates atramentum as carbon black or vitriol, respectively.

8 Charles R. Dodwell, Theophilus, De diversis artibus. Theophilus, the Various Arts. Translated from the Latin with Introduction and Notes (London: Thomas Nelson, 1961), pp. 34-35.

9 Zerdoun, Les encres noires (cit. note 7), p. 117. 
were used to extract gallic or tannic acids from gall nuts - diseased formations on the leaf buds, leaves, and fruits of various species of oak, caused when parasitoid wasps deposit their eggs in them - and tree bark. Iron(II) sulfate (also known as 'green vitriol' because of its colour and its glassy appearance) is the most frequently named ingredient in ink formulas. Natural vitrio ${ }^{10}$ consists of a mixture of metallic sulfates (iron sulfate, copper sulfate, manganese sulfate, zinc sulfate, etc.) with relative weight contributions characteristic of the source or purification procedure." Since their elemental composition is rich in metals that are easily detected by the X-Ray Fluorescence (XRF) analysis, it has become the method of choice for identification and classification of iron-gall inks. This technique benefits from the availability of a variety of transportable instruments ranging from single spot to high-resolution scanning equipment, as well as from a wealth of knowledge and experience that has been accumulated in the characterization of historical inks via this technique. Specifically, the development and use of the fingerprint model, based on the quantitative and semi-quantitative determination of inorganic ingredients normalized to iron, as a main ingredient of the iron-gall inks, allows their reliable classification. ${ }^{12}$

Microscopically, iron-gall inks appear highly inhomogeneous in colour and texture, with traces of dark crystals. They gradually lose opacity in the near-infrared region and become invisible under infrared light of ca. $1400 \mathrm{~nm}$. Finally, they display a characteristic spectrum when investigated by Raman spectroscopy. ${ }^{13}$ Since the inks contain both soluble and insoluble parts, they usually penetrate a substrate such as paper but display a preferential penetration on the flesh side of parchment.

Medieval iron-gall inks, with their distinct metallic fingerprint, also attract a great deal of attention. Recent technological developments in the field of non-destructive testing and growing interdisciplinary collaborations have led

10 Deatiled account of historic use of the vitriol lies beyond the scope of this article. Vladimir Karpenko and John A. Norris (Chem. Listy, 2002, 96. 997-1005) offer detailed account of the terminology and sources of vitriol in Antiquity and Middle Ages.

11 Christoph Krekel, "Chemische Struktur historischer Eisengallustinten," in G. Banik and H. Weber (eds), Tintenfraßschäden und ihre Behandlung, Werkhefte der staatlichen Archivverwaltung Baden-Württemberg, Stuttgart: Kohlhammer, pp. 25-36 (Serie A Landesarchivdirektion, 10).

12 Oliver Hahn, "Eisengallustinten - Materialanalyse historischer Schreibmaterialien durch zerstörungsfreie naturwissenschaftliche Untersuchung," Editio, Internationales Jahrbuch für Editionswissenschaft 2006, pp. 143-157.

13 Alana Lee, Vincent Otieno-Alego, Dudley C. Creagh, "Identification of Iron-Gall Inks with Near-Infrared Raman Microspectroscopy," Journal of Raman Spectroscopy, 2008, 39:1079-1084. 
to a broadening of the field of codicology to include experimental characterization of writing materials. In this new field, we work together with papyrologists, codicologists and palaeographers, who include the primary tests of the inks in their studies choosing representative manuscripts for in-depth characterization. ${ }^{14}$ Interestingly, in the Middle East, a multitude of various recipes and scarcity of analytic data contrasts strongly with the situation in Europe, where the first recipes do not appear before the 12th century; but a multitude of analytic results clearly demonstrates that by that time the iron-gall inks had already become a dominant ink type all over Europe.

To facilitate the interdisciplinary work, we have developed a three-step standard protocol for the determination of ink composition. Our protocol uses mobile and non-invasive equipment to conduct the studies on site and consists of a primary screening to broadly classify the ink as carbon, plant (tannin) or iron-gall. This is followed by the determination of the elemental composition using X-ray fluorescence spectrometry (XRF) and a subsequent in-depth analysis using vibration spectroscopic techniques: FTIR and Raman. The primary screening is carried out by means of NIR (near infrared radiation) reflectography. As mentioned above, optical differences between carbon, plant (tannin) and iron-gall inks are best recognized by comparing their response to infrared, rather than near-infrared light: carbon ink has a deep black colour, iron-gall ink becomes transparent above $1400 \mathrm{~nm}$ and tannin ink disappears at about $75^{\circ} \mathrm{nm} .{ }^{15}$ We have simplified the analysis using a small usB microscope with built-in NIR (940 nm) and UV (395 nm) LED in addition to an external white

14 Ira Rabin, "Building a Bridge from the Dead Sea Scrolls to Mediaeval Hebrew Manuscripts," in Jewish Manuscript Cultures. New Perspectives, edited by I. Wandrey, (Berlin/ Boston: De Gruyter, 2017), pp. 309-322; Ira Rabin, "Instrumental Analysis in Manuscript Studies in Comparative Oriental Manuscript Studies. An Introduction," edited by A. Bausi et al. (Hamburg: COMSt; Tradition, 2015), pp. 27-30; Denis Nosnitzin and Ira Rabin, "A Fragment of an Ancient Hymnody Manuscript from Mə’əsar Gwəhila (Təgray, Ethiopia)," Aethiopica, 2014, 17:65-77; Ira Rabin, Oliver Hahn, Marcello Binetti, "Inks of Medieval Hebrew Manuscripts: A Typological Study," Manuscript Cultures, 2014, 6:119-131; Ira Rabin, Oliver Hahn, and Miriam Geissbühler, "Combining Codicology and X-Ray Spectrometry to Unveil the History of Production of Codex Germanicus 6 (Staats- und Universitätsbibliothek Hamburg)," Manuscript Cultures, 2015, 7:126-131; Miriam Geissbühler, Georg Dietz, Oliver Hahn, and Ira Rabin, "Advanced Codicological Studies of Cod. germ. 6: Part 2," Manuscript Cultures, 2018, 11:133-140; Marco Heiles, Ira Rabin, and Oliver Hahn, "Palaeography and X-Ray Fluorescence Spectroscopy: Manuscript Production and Censorship of the Fifteenth Century German Manuscript, State and University Library Hamburg, Cod. germ. 1," Manuscript Cultures, 2018, 11:109-139.

15 Ralf Mrusek, Robert Fuchs, and Doris Oltrogge, "Spektrale Fenster zur Vergangenheit Ein neues Reflektographieverfahren zur Untersuchung von Buchmalerei und historischem Schriftgut," Naturwissenschaften, 1995, 82:68-79. 


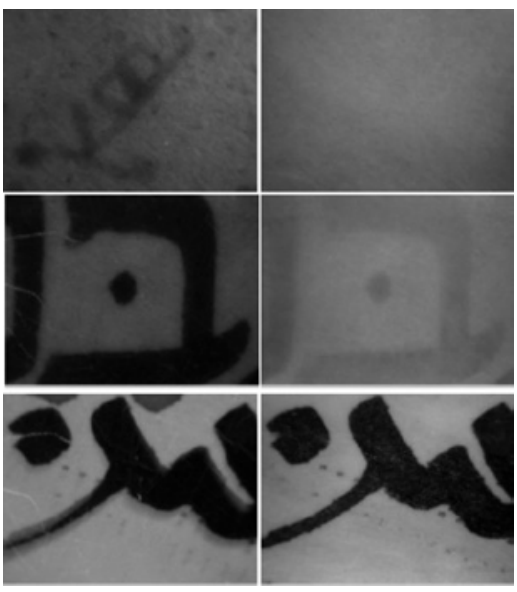

FIGURE 4.1

Visible (left) and NIR (right) images letters written with typologically different inks. Upper row: plant (tannin) ink; middle row: iron-gall ink; bottom row: carbon ink

light source.$^{16}$ Comparing the images under white and near-infrared illumination, we determine the ink typology by observing changes in the opacity of the ink. Here, carbon-based inks (Fig. 4.1, bottom row) show no change in their opacity when illuminated with NIR wavelength, while the opacity of iron-gall inks changes considerably (Fig. 4.1, middle row) and plant (tannin) inks become transparent (Fig. 4.1, upper row). Usually, our partners from the Humanities include the first step of the protocol in their manuscript assessment.

The second step of the protocol consists of the XRF analysis to obtain contributions of the inorganic components of the ink under investigation. In the case of iron-gall inks, we establish the fingerprints, i.e. the characteristic ratios of the vitriolic components of the ink (Fig. 4.2). In the case presented in Fig. 4.2 we addressed a specific question: whether composition of the ink would support paleographic attribution of three fragments to a single manuscript. The analysis shows that the fingerprint of the ink, the ratio of copper / iron and zinc / iron is indeed constant in all three fragments, supporting the hypothesis of a single manuscript. In contrast, the ink of the vowel displays a different fingerprint confirming that the vocalization points were not written together with the consonantal text.

In the case of carbon-based inks, XRF analysis serves to discover the presence of metals and identify mixed inks, i.e. inks produced by addition of various metals to the soot inks and intentional mixing of iron-gall and soot-based inks, respectively. Mixed inks have received no or little attention in scholarly

16 Ira Rabin, Roman Schütz, Anka Kohl, Timo Wolff, Roald Tagle, Simone Pentzien, Oliver Hahn, and Stephen Emmel, "Identification and Classification of Historical Writing Inks in Spectroscopy," Comparative Oriental Manuscript Studies Newsletter, 2012, 3:26-30. 


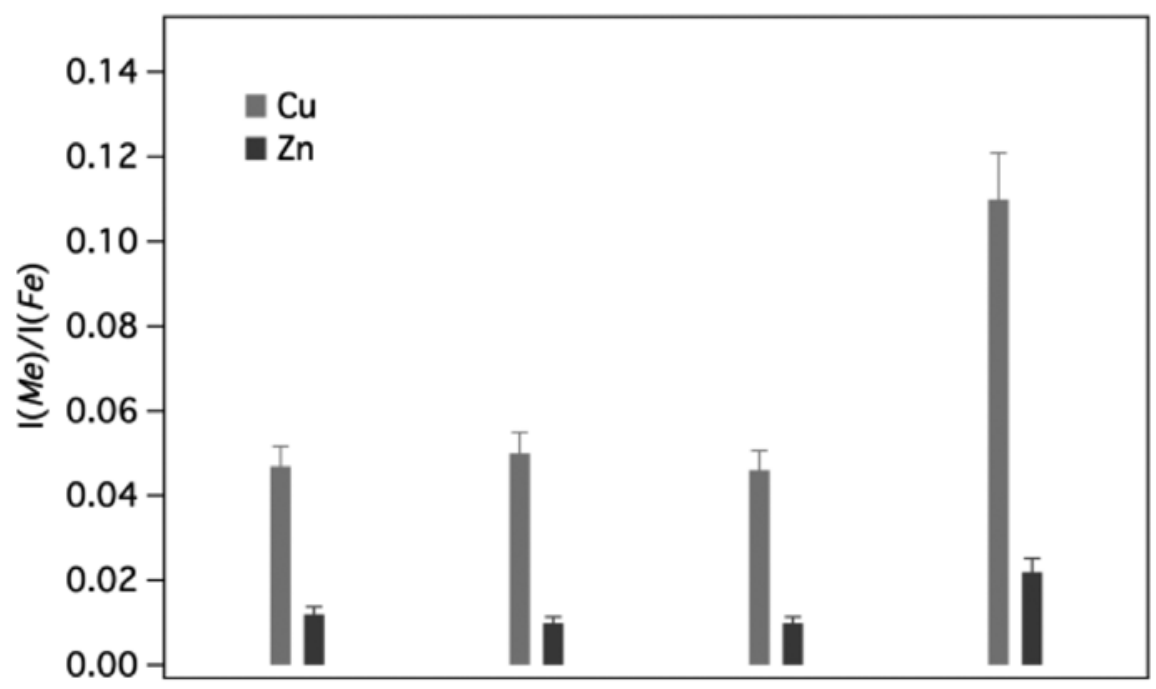

\section{T-S F17.4 T-S 12.755 T-S 12.756 T-S 12.755 vowel}

FIGURE 4.2 Comparison of the fingerprint of writing ink in the fragments T-S F17.4, T-S 12.755 and T-S 12.756 (Cambridge University Library). Intensities of the metallic components, copper ( $\mathrm{Cu}$, grey) and zinc ( $\mathrm{Zn}$, black), are normalized to that of iron $(\mathrm{Fe})$. Here, ink analysis demonstrated that three different fragments belong to the same manuscript

and material studies because their identification and recognition of their importance are recent discoveries. Yet, judging by the Arabic medieval ink recipes, mixed inks played an important role in the Islamicate world. ${ }^{17}$ Their detection, and especially their classification, is quite difficult if one is limited to non-invasive methods. In the third step of our protocol, used for these specific cases, we perform FTIR spectroscopy to collect information on the chemical composition of the binders and Raman spectroscopy to determine the co-presence of carbon and iron-gall ink.

The analytic studies of the inks indicate that typologically distinct inks existed as early as the 3 rd century вСЕ. ${ }^{18}$ It must be noted that the oldest extant recipe of a predecessor of the iron-gall ink is authored by Philo of Byzantium,

17 Claudia Colini, Oliver Hahn, Olivier Bonnerot, Simon Steger, Zina Cohen, Tea Ghigo, Thomas Christiansen, Marina Bicchieri, Paola Biocca, Myriam Krutzsch, and Ira Rabin, "The Quest for the Mixed Inks," Manuscript Cultures 2018, 11:41-48.

18 Elisabeth Delange, Maurice Grange, Bruce Kusko, Eve Menei, "Apparition de l'encre métallogallique en Égypte à partir de la collection de papyrus du Louvre," Revue d'Égyptologie, 199o, 41:213-217. 
who lived in about the same time. ${ }^{19}$ Pliny's detailed account of the manufacture of various soot-based inks in the 1st century CE indicates that, despite its apparent simplicity, the production of high-quality, pure soot was not an easy task in antiquity. ${ }^{20}$ His account fits well with the scientific results of the

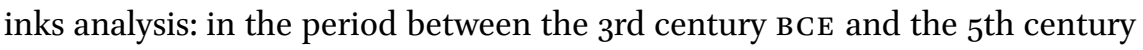
$\mathrm{CE}$, we find various black writing inks that can be roughly grouped in the following types: pure soot or charcoal-based inks; soot inks with the addition of copper or lead; mixed inks containing soot and iron-gall inks or tannins; and pure iron-gall inks. It is rather tempting to correlate the emergence of such a variety with the growing need for ink and experimentation to substitute rather expensive carbon inks, the main writing ink of antiquity: it could be viewed as a by-product of the expansion of the bureaucracy needed for the proper functioning of the expanding empire, following the conquests of Alexander the Great. On the other hand, finding a great variety of inks might simply reflect the growing number of analyses conducted in recent decades. Christiansen, for instance, suggests that metals in the soot inks appear due to their presence in the metallurgical soot used as a precursor in Egypt. ${ }^{21}$ In such a case, we would also expect to find metals in the inks of pharaonic Egypt. However, the lack of reference to metallurgical soot in the chapters dedicated to the inks in the books of Pliny the Elder supports our skepticism about this explanation.

It is unfortunate that the scarcity of known recipes from the period under investigation (i.e. 3 rd century BCE and 7th century CE) cannot account for the variety of inks detected analytically. There is an urgent need to reassess the written sources, paying specific attention to the production of writing black inks. Interestingly, all the extant early recipes for metal-containing inks always refer to copper-based substances rather than iron, though only iron ions produce black precipitate upon reaction with galls. ${ }^{22}$ The clear distinction between copper and iron sulphates probably marks the beginning of the iron-gall inks era. On one hand, our preliminary results indicate that iron-gall ink seems to be established by the $5^{\text {th }}$ century $\mathrm{CE}$, at least in the Middle East. On the other

19 Zerdun, Les encres noires, (cit. note 7), p. 93.

20 Pliny, Naturalis historia, Book xxxv <http://www.perseus.tufts.edu/hopper/text?doc= Plin.+Nat.+toc> (last accessed 13th March 2019); see also Pliny, The Natural History (cit. note 3$)$.

21 Thomas Christiansen, "Manufacture of Black Ink in the Ancient Mediterranean," Bulletin of the American Society of Papyrologists 2017, 54:167-195.

22 Recently mixed inks containing soot inks and a copper based precursor of iron-gall ink were found on a documentary Greek papyrus stored in Florence. See Ira Rabin, Carsten Wintermann, Oliver Hahn, "Ink Characterization, Performed in Biblioteca Medicea Laurenziana (September 2018)," Analecta Papyrologica, 2019, XXXI:301-316. 
hand, it seems that the knowledge that iron sulphate (green vitriol) rather than copper sulphate (blue vitriol) is needed for production of black inks is far from universal in the 1oth century CE. ${ }^{23}$

We hope that routine studies of the inks in a statistically relevant number of manuscripts originating over a larger period of time will reveal a coherent picture of the development and trade in the black writing inks. Moreover, we are confident that an extensive ink database would serve as a non-invasive dating and localizing tool for a large number of manuscripts of unknown provenance. Currently, no such a tool exists. In many cases, for which dating is crucial, we are limited to the invasive radioactive carbon method that dates organic writing surfaces rather than inks.

\section{$4 \quad$ Conclusions}

The great variety of writing inks appear in the centuries around the turn of the Christian era. The first step of our protocol developed for an easy ink recognition is pertinent for differentiating between pure-type inks, such as carbon, plant and iron-gall inks. Yet, the presence of metals in carbon-based inks can be discovered only if the second step of the protocol, i.e. the XRF analysis, is carried out. We therefore recommend including this step in the study of inks, also when a reflectographic test reveals the sooty nature of an ink. In the specific case that XRF analysis detects the presence of iron, we recommended using the third step of the protocol to differentiate between mere metallic iron and a proper mixture of soot and iron-gall ink.

23 See Claudia Colini's chapter in this volume (Chapter 7). 